\title{
Outcomes of the Ross Procedure in the Pediatric Population
}

\author{
Anton A. Lukyanov*; Yuriy N. Gorbatyh, PhD,ScD; Alexander V. Bogachev-Prokofyev, \\ $\mathrm{PhD}$; Yuriy L. Naberuchin, $\mathrm{PhD}, \mathrm{ScD}$; Alexander Yu. Omelchenko, PhD; \\ Timur S. Khapaev, PhD; Alexander M. Karaskov, $\mathrm{PhD}, \mathrm{ScD}$ \\ Academician E.N.Meshalkin Novosibirsk Research Institute of Circulation Pathology \\ Novosibirsk, the Russian Federation
}

\begin{abstract}
The Ross procedure (RP) is considered by many authors as the best option for aortic valve replacement in young children and adolescents. This paper presents the results of the immediate and late postoperative period (more than 5 years) after the RP among pediatric patients.
\end{abstract}

Keywords: Ross procedure; pediatric population; immediate results; long term outcome.

\section{Introduction}

Congenital anomalies of the aortic valve account for up to $8 \%$ of all congenital heart malformations. In general, the proportion of pathology of the aortic valve is $30-35 \%$ of patients with valvular heart disease, ranking second after mitral valve disease. The relatively high incidence of the congenital and acquired diseases of the aortic valve and aortic root necessitates a constant search for the best options for its surgical correction and optimization of the existing methods [1].

The RP, using the native pulmonary autograft as the aortic valve, provides good hemodynamic parameters in children with growth potential and eliminates the need for anticoagulants. However, to date, this method of aortic valve restoration in pediatric patients as a radical procedure is still being debated [2].

Some researchers consider this technology very effective for the correction of aortic valve disease in the whole pediatric population: in young children as well as adolescents $[3,4]$. However, an analysis of recent literature on the subject reveals that, despite the numerous publications, long-term effects of the RP in pediatric patients, in comparison with those for other types of operations, remain poorly studied.

*Corresponding author: Anton A. Lukyanov, Center for Pediatric Cardiac Surgery and Neonatal Surgery of the Academician E.N.Meshalkin Novosibirsk Research Institute of Circulation Pathology.Novosibirsk, Russia.E-mail: anthony1206@rambler.ru
Such studies would enable the effectiveness of this procedure to be assessed in the long term, to clarify the indications for its conduct in patients with different types of aortic defects, and to optimize the selection criteria. In this regard, the study of the immediate and long-term results of the RP in the pediatric population can be a very relevant and meaningful.

The aim of this study was to examine the results of the immediate and late postoperative period (more than 5 years) after the RP among the pediatric patients treated at the Center for Pediatric Cardiac Surgery of the Academician E.N. Meshalkin Novosibirsk Research Institute of Circulation Pathology (NRICP).

\section{Material and Methods}

The early and long-term results of the RP were analyzed using the data from 114 pediatric patients who were operated at the Center between 2002 and 2012. The study was approved by Ethics Committee of the NRICP. Written informed consent was obtained from the child's parents.

The age of patients ranged from 12 days to 18 years. The age distribution was as follows: $3(2.6 \%)$ patients between 12 days and 1 year, $18(15.8 \%)$ patients between 1 and 7 years, 72(63.2\%) patients between 7 and 16 years, 21(18.4\%) patients between 16 and 18 years. The average body weight of the patientswas $39.17 \pm 17.93 \mathrm{~kg}$ (between 2.9 and $87 \mathrm{~kg}$ ).

In accordance with the diagnosis, the distribution of the operations patients received was as follows: isolated aortic valve stenosis (IAVS) in 38(33.3\%), aortic valve insufficiency 
(AVI) in $33(28.9 \%)$, and mixed lesion (ML) in 56(49.1\%). Total aortic root replacement by pulmonary autograft with reimplantation of the coronary arteries in the wall of the pulmonary autograft by type «total root replacement» was performed in 105(88.2\%) patients. The subcoronary insertion technique was applied in $14(15.9 \%)$ cases. To replace the valve in the pulmonary position we used the pulmonary allografts (homografts) in 24(21.1\%) cases and xenograft in 90(78.9\%) cases. Among the xenografts, there were "Kemerovo" AV composite (diepoxy-treated xenoconduit) in 40(44.4\%) cases, "BioLAB" (glutaraldehyde-treated xenoconduit) in 17(18.9\%) cases, and "Contegra" in 12(33.3\%) cases. The average diameter of the conduit implanted in the pulmonary position was $23.54 \mathrm{~mm}$.

We used hypothermic extracorporeal circulation and Custodiol cardioplegia with external cooling of the heart with crushed ice. The extracorporeal circulation time (ECCT) lasted from 144 to $730(244.2 \pm 42.7)$ minutes and the time of the aortic occlusion ranged from 90 to $282(172.2 \pm 42.7)$ minutes.

The postoperative course was evaluated in terms of mortality and complication rates. In the long term, we analyzed the frequency of the reoperations, mortality rate, and the dynamics of the echocardiographic parameters.

Mean follow-up time was $3.9 \pm 1.9$ years (from 1 to 9 years). The examination included at least two echocardiographic examinations (with transthoracic and transesophageal probes), one catheterization of the cardiac chambers, angiocardiography, and selective aorto-coronary angiography.

Statistical analysis was performed using the statistical software Statistica 7.0 for Windows. We used the chi-square test with the Yates' correction to compare the frequency of the binary trait in two unrelated groups of paired comparisons. For data with normal distribution, inter-group comparisons were performed using Student's t-test. The Mann-Whitney (U Test) was used to compare the differences between the two independent groups (for nonparametric data). We also applied the Cox regression model and the Kaplan-Meier method. The value of $P<0.05$ was considered significant.

\section{Results}

The average length a patient's stay in the intensive care unit after surgery was $3.48 \pm 2.90$ days; the average period of hospitalization was $24.70 \pm 10.87$ days. The mortality in the early postoperative period was $2.1 \%$ and the total complication rate was $51.5 \%$. Among the complications, the most frequent were pericardial effusion $(25.6 \%)$, cardiac and respiratory failure $(7.6 \%)$, and cardiac arrhythmias $(6.1 \%)$. To evaluate the factors affecting the incidence of complications in the hospital period, correlation analysis was performed. The relationship between the frequency of the complications in the hospital period and the child's age $(r=0.18 ; P=0.24)$ and weight $(r=0.22 ; P=0.12)$ was weakly positive. Between the frequency of the complications and LVEF, a statistically significant inverse correlation of moderate intensity was found $(r=-0.42 ; \quad P=0.021)$. The frequency of the complications weakly correlated with RVEDVI $(r=0.29 ; P=0.52)$. The frequency of pericardial effusion was associated with the type of conduit: $r=0.35(P=0.34)$ for Contegra, $r=0.33(P=0.007)$ for diepoxy-treated xenoconduit "Kemerovo", and $r=0.42$ $(P=0.014)$ for glutaraldehyde-treated xenoconduit "Biolab".

The data obtained indicate a number of factors that can be considered as criteria for prediction of outcomes of the RP in children in the postoperative period. The results of multivariate regression analysis confirmed the data of the correlation analysis and led to the conclusion that some factors presented in Table 1 can be identified as the predictors of postoperative complications, such as pericardial effusion and cardiac and respiratory failure.

Table 1.

Risk factors for postoperative complications after the $R P$ in accordance with the data of multivariate regression analysis

\begin{tabular}{|l|c|c|c|c|}
\hline & \multicolumn{2}{|c|}{ Pericardial effusion } & \multicolumn{2}{c|}{$\begin{array}{c}\text { Cardiac and respiratory } \\
\text { failure }\end{array}$} \\
\hline \multicolumn{1}{|c}{ Factors } & OR $(95 \% \mathrm{CI})$ & $P$ & OR $(95 \% \mathrm{CI})$ & $P$ \\
\hline Age & $1.30(0.89-5.13)$ & 0.042 & $3.59(1.28-5.36)$ & 0.004 \\
\hline Body weight & $1.62(0.44-2.15)$ & 0.012 & $1.22(1.39-5.65)$ & 0.082 \\
\hline NYHA class & $2.14(1.30-3.62)$ & 0.005 & $1.84(1.54-3.65)$ & 0.052 \\
\hline LV EF & $2.78(0.68-4.51)$ & 0.014 & $1.26(0.98-5.33)$ & 0.054 \\
\hline ECCT & $3.48(1.15-5.21)$ & 0.003 & $1.28(0.96-5.24)$ & 0.039 \\
\hline LVEDVI & $0.28(0.14-1.64)$ & $<0.0001$ & $2.14(0.74-3.22)$ & 0.015 \\
\hline RVEDVI & $0.14(0.04-1.43)$ & $<0.0001$ & $3.86(1.49-5.63)$ & 0.008 \\
\hline Homograft & $1.95(0.28-3.15)$ & 0.033 & $0.45(0.19-1.76)$ & $<0.0001$ \\
\hline «Contegra" & $0.86(0.24-2.18)$ & 0.006 & $0.28(0.06-1.12)$ & $<0.0001$ \\
\hline $\begin{array}{l}\text { "Kemerovo" } \\
\text { xenoconduit) }\end{array}$ & $2.14(1.78-6.27)$ & 0.041 & $0.32(0.12-1.37)$ & $<0.0001$ \\
\hline $\begin{array}{l}\text { "BioLab" } \\
\text { xenoconduit) }\end{array}$ & $2.28(1.98-6.97)$ & 0.055 & $0.18(0.04-1.02)$ & $<0.0001$ \\
\hline
\end{tabular}

Thus, among the factors associated with the development of cardiac and respiratory failure, LVEDVI, RVEDVI, and age of children were the most significant predictors. Types of conduits were associated with a risk of pericardial effusion developing, the main negative factors being the diepoxytreated and glutaraldehyde-treated xenoconduits implanted into the right-sided position. Along with these factors, it should also be mentioned that NYHA class, LV EF, and ECCT play a negative role in the development of this complication.

In the postoperative period, in the group from 1 to 9 years of age, 104 patients were examined. The death rate in the late postoperative period was only $1.14 \%$, and the actuarial survival in the long-term period after surgery reached $98.86 \%$.

Based on a catamnestic evaluation of echocardiographic parameters, we did not find signs of autograft valve insufficiency during the entire observation period. Also, there was no significant dilatation of the autograft root. Increasing of the autograft diameter was parallel to somatic growth of the observed patients. There were no significant changes in the value of the systolic pressure gradient across the implanted autograft valve compared with the value at the time of discharge (Table 2). 
Table 2.

Systolic pressure gradients and Z- score on the autograft valve

\begin{tabular}{|l|c|c|c|}
\hline \multirow{2}{*}{ Parameters } & \multicolumn{3}{|c|}{ Period after surgery } \\
\cline { 2 - 4 } & $1-2$ years & $3-4$ years & $\geq 5$ years \\
\hline LV/Ao gradient & $6.1 \pm 1.9$ & $6.7 \pm 2.7$ & $8.5 \pm 3.4$ \\
\hline Z- score & $1.19 \pm 0.10$ & $1.28 \pm 0.14$ & $1.32 \pm 0.18$ \\
\hline
\end{tabular}

The frequency of reoperations in the late postoperative period was $23.7 \%$. At the same time, we would like to emphasize that autograft dysfunction, which required reoperations during the observation period, was not observed; the main reason for reoperations was conduit dysfunction in the pulmonary artery position.

The most frequent cause of pulmonary conduit dysfunction was valve calcification $(52 \%$ of cases, $n=12)$. Conduit wall calcification was observed less frequently, in $30 \%$ of cases $(n=7)$. Calcification at the distal anastomotic level was noted in $17 \%$ of the cases $(n=4)$.

For a more complete characterization of the RP efficiency in the long term, a comparative analysis of the frequency of reoperations after the RP and aortic valve replacement during the 5-year follow-up was performed. We found that freedom from reoperation after the $\mathrm{RP}$ and aortic valve replacement was $97 \%$ and 94\%, respectively (Fig.1); a Cox-Mantel test revealed no significant intergroup differences.

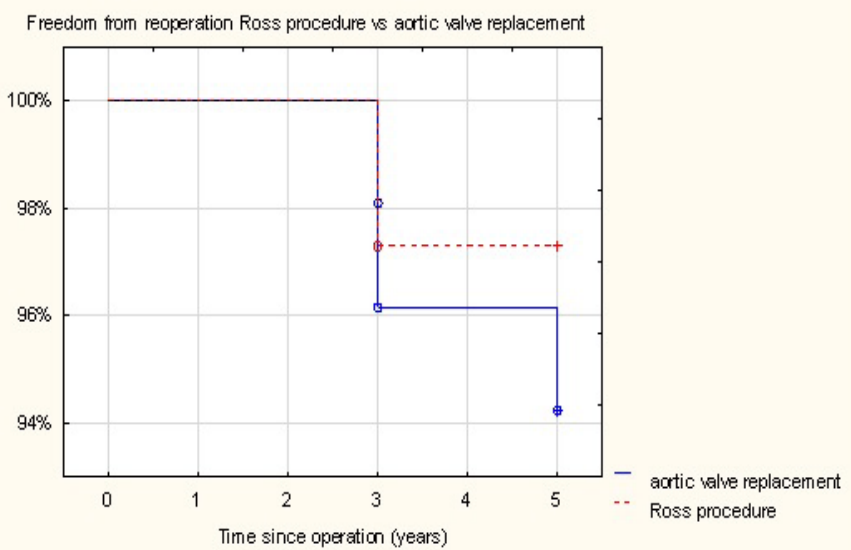

Figure 1. Freedom from reoperation after the RP and aortic valve replacement

Correlation analysis revealed a number of statistically significant relationships between the studied parameters and the freedom from reoperations in the long term. Thus, the frequency of reoperations was moderately positively associated with age $(r=0.38 ; P=0.004)$ and male gender $(r=0.31 ; P=0.78)$. At the same time, we discovered a moderate negative correlation between this parameter and the EF of both ventricles (RV $-r=-0.35 ; P=0.011 ; \mathrm{LV}-r=-0.40 ; P=0.036$ ). We also found a moderate positive correlation between the frequency of reoperations and the RV/LA gradients $(r=0.39$, $P=0.009$ for mean value and $r=0.42, P=0.040$ for peak value) and the ratio of the Ao/LA ring diameters $(r=0.45 ; P=0.001)$. The relationship with ECCT was less pronounced $(r=0.28$; $P=0.028)$.
The frequency of reoperations depended on the type of conduits. Negative correlations were found with Contegra $(r=-$ 0.38 ; $P=0.001)$ and homograft $(r=-0.26$; $P=0.026)$; positive correlations were found with the diepoxy-treated $(r=0.31$; $P=0.47)$ and glutaraldehyde-treated $(r=0.48 ; \quad P=0.02)$ xenoconduits. Unfortunately, the relatively small sample size limited a more detailed analysis.

The Cox regression model and the Kaplan-Meier method allowed us to establish the number of risk factors for reoperations due to conduit dysfunction in the right-sided positions after the RP. As can be seen from the obtained data, significant factors in the late postoperative period are the RV/LA gradients $(P=0.012)$ (peak and mean values), $\operatorname{RVEF}(P=0.035)$, and to a lesser degree, the ratio of the Ao/ LA ring diameters. CPBT $(P=0.042)$, which characterizes the technical complexity of the operation, can also be a predictor of reoperations in the long term (more stitches for bleeding, malposition conduit et al.).

As noted previously, the risk of operations was also related to the type of conduit used. It was found that the probability of dysfunction was greater with use of xenografts (Fig.2).

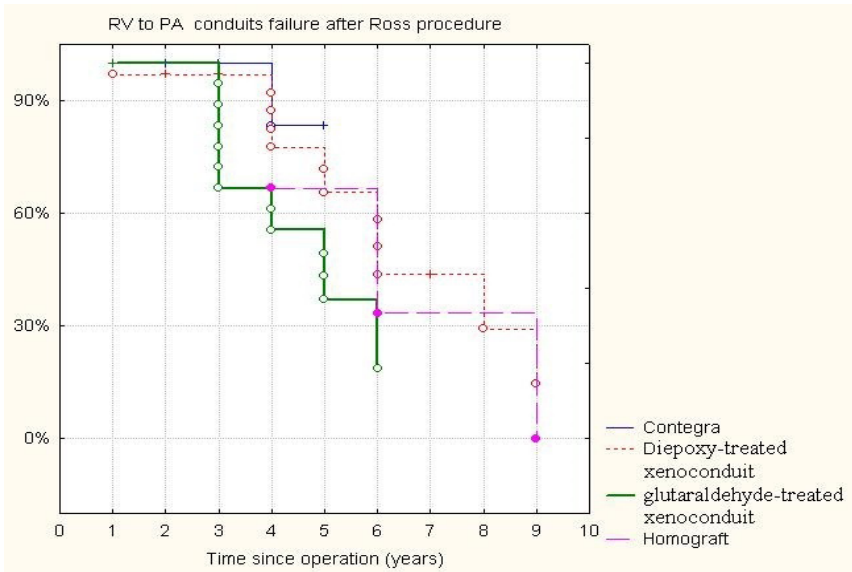

Figure 2. Conduit dysfunction in the pulmonary position after the $R P$

\section{Discussion}

In our study, the frequency of deaths in the early and longterm periods after the RP was $6.14 \%$ and $1.14 \%$, respectively; actuarial survival in the long term was $98.86 \%$. These data are consistent with the results obtained in other studies, where mortality in the pediatric group after the RP during 6.1 years of follow-up was $2.6 \%$, and the 5- and 10-year survival rates were at $93.9 \%$ and $90.4 \%$, respectively. If we compare these data with the frequency of deaths in open commissurotomy, the advantages of the RP become apparent. According to the data presented by various authors for open commissurotomy, the mortality ranges from 3 to $25 \%$, averaging $12 \%$, i.e., several times higher than for the RP [5-7].

The complication rate in our study was higher than the rate according to the data in the literature. For example, the study of T. Karamlou et al. showed that the complications 
in the postoperative period were diagnosed in only 10 of 53 patients, whereas in this study the overall complication rate reached $51.5 \%$ [8]; however, differences in the structure of the complications were minor. In a study by $\mathrm{T}$. Karamlou et al. and our study, pericarditis and cardiac arrhythmias were the leading complications, but T. Karamlou et al. also noted a relatively high incidence of bleeding in the postoperative period, whereas in our study, the pericardial effusion and cardiac/respiratory failure were observed more frequently.

In our study, the clinical efficacy of the RP was also demonstrated by the dynamics of hemodynamic parameters. Thus, in the early postoperative period, there was a trend toward a reduction of the left ventricle cavity, an increase in its contractility and a decrease in its stroke volume, and a decrease in systolic pressure gradient between the left ventricle and the ascending aorta in patients with IAVS. In addition, we have registered the absence of the hemodynamically significant systolic pressure gradients and regurgitation on the substituted valves in the left- and right-sided positions.

However, repeated operations over several years are almost inevitable. According to our data, the frequency of reoperation was $23.7 \%$; the main indication for reoperation was conduit dysfunction in the pulmonary position, whereas cases of autograft dysfunction were not recorded. The authors of other studies also indicated that the autograft dysfunction was rare. According to the International Registry of the $\mathrm{RP}$, the frequency of such complications is less than $1 \%$. [6]. Comparison of the freedom from reoperations after the Ross procedure and other types of surgical interventions on the aortic valve revealed no significant difference. At the same time, according to other studies, in a 10-year followup reoperations were required in $26 \%$ of patients after aortic valve replacement and $28 \%$ of patients after an open commissurotomy $[8,9]$. When comparing the results of our study with the above-mentioned data, their longer duration of the follow-up must be taken into account; at the same time, the identified trends are very revealing because they were based on an analysis of a large single-center study.

In summary, it can be stated that the RP has a number of advantages for pediatric patients over other types of surgical interventions on the aortic valve. This procedure provides normalization of hemodynamic parameters, provides the growth potential for autograft proportionally to the child's growth, and (very important) demonstrates a high level of safety for the patient and positive long-term results. These findings are in agreement with the published data [10,11]. The listed advantages of the Ross procedure, despite its technical complexity, indicate that it is the best type of surgical intervention in aortic valve replacement in children. Risk factors for postoperative complications and reoperations, which were identified in our study, will clarify the selection criteria for the operation, as well as aid in developing new preparation schemes for surgery and protocols for the postoperative period, which will further improve the safety and efficacy of the RP.

\section{Competing interests}

The authors declare that they have no competing interests.

\section{References}

1. Lukyanov AA, Gorbatykh YN, Omelchenko AY, Naberuchin YL, Ivanov AA, Gorbatykh AV, et al. The Ross procedure in congenital aortic valve disease surgery, graft selection. J Pathol Blood Circul Heart Surg 2013; 4:63-4. [Article in Russian].

2. Bechtchel JF, Bartels C, Schmidtke C, Skibba W, MullerSteinhardt M, Kluter H, et al. Does histocompatibility affect homograft valve function after the Ross procedure? Circulation 2001; 104(12 Supp 1):125-8.

3. Hörer J, Bening C, Vogt M, Martin K, Cleuziou J, Tassani-Prell $\mathrm{P}$, et al. Predonation of autologous blood reduces perioperative allogenic transfusion requirement in grown-up patients with congenital heart disease. Eur J Cardiothorac Surg 2010; 37(5):991-5.

4. Brown JW, Rodefeld MD, Ruzmetov M, Eltayeb O, Yurdakok O, Tourentine MW. Surgical valvuloplasty versus balloon aortic dilation for congenital aortic stenosis: are evidence-based outcomes relevant? Ann Thorac Surg 2012; 94(1):146-53.

5. Lambert V, Obreja D, Losay J, Touchot-Kone A, Piot JD, Serraf A, et al. Long-term results after valvotomy for congenital aortic valvar stenosis in children. Cardiol Young 2000; 10(6):590-6.

6. Hazekamp MG, Grotenhuis HB, Schoof PH, Rijlaarsdam ME, Ottenkamp J, Dion RA. Results of the Ross operation in a pediatric population. Eur J Cardiothorac Surg 2005; 27(6):975-9.

7. Charitos EI, Takkenberg JJ, Hanke T, Gorski A, Botha C, Franke U, et al. Reoperations on the pulmonary autograft and pulmonary homograft after the Ross procedure: An update on the German Dutch Ross Registry. J Thorac Cardiovasc Surg 2012; 144(4):813-21.

8. Karamlou T, Jang K, Williams WG, Caldarone CA, VanArsdell G, Coles JG, et al. Outcomes and associated risk factors for aortic valve replacement in 160 children: a competing-risks analysis. Circulation 2005; 112(22):3462-9.

9. Dzemeshkevich S L, Stephenson LU, Alexi-Meskhishvili VV. Diseases of the aortic valve. Moscow; 2004.

10. Karaskov AM, Gorbatykh YN, Zheleznev SI, Turaev FF. Influence of initial indicator of patients on results prognostication for Ross procedure. J Pathol Blood Circul Heart Surg 2009; 3:86-90. [Article in Russian].

11. Elder RW, Quaeqebeur JM, Bacha EA, Chen JM, BourlonF, Williams IA. Outcomes of the infant Ross procedure for congenital aortic stenosis followed into adolescence. J Thorac Cardiovasc Surg 2013; 145(6):1504-11. 